\title{
ADAGIA SEPTENTRIONALIA - EHR-ERINNERUNG AN MATTI KUUSI
}

\author{
Vilmos VOIGT \\ 1113 Budapest, Tarcali u. 22/a, Ungarn
}

\begin{abstract}
Reminiscences on Matti Kuusi (1914-1998), Finnish folklorist and cultural personality, innovator of Finno-Ugric and comparative paremiology, as well as of Finnish folk epic poetry.

Keywords: Matti Kuusi, paremiology, Finnish folk poetry
\end{abstract}

Das 20. Jahrhundert ist eine Blütezeit der vergleichenden Parömiologie. Um nur einige Riesengestalten zu nennen: Archer TAYLOR, Démétrios LOUKATOS, Lutz RÖHRICH, und viele, in Europa zu Unrecht unbekannt gebliebene amerikanische Philologen haben diese Disziplin zu einem unerwarteten Höhepunkt geführt. Und auch die nächste Generation hat schon ihr Profil geprägt: Joseph Aquilina, G. L. Permuakov, Arvo Krikmann, Kazys Grigas, Gyula Paczolay und Peter GRZYBEK sind schon Klassiker einer weiteren Erneuerung unseres Faches. Und Wolfgang MIEDER leitet dieses Großorchester seit vielen Jahren mit beispielloser Energie. Doch der markanteste Parömiologe unseres Zeitalters war zweifellos der führende finnische Folklorist Matti KUUSI, den viele von uns auch persönlich gut gekannt haben.

Seine Lebensdaten sind bekannt. Er wurde am 25. März 1914 in Helsinki geboren. Der auffallend talentvolle Literator studierte (1932-1939) an der Universität von Helsinki Finnisch und Latein (!). Er hat viel im Folklore-Archiv der Finnischen Literarischen Gesellschaft (SKS) gearbeitet, offiziell wirkte er aber als Dozent (1951-1959), später als Professor (1959-1977) am Lehrstuhl der „finnischen und vergleichenden Folkloristik" an derselben Universität. 1985 wurde er zum Mitglied der Finnischen Akademie ernannt. In den letzten 20 Jahren hörte man immer wieder von Krankheiten über ihm, aber auch von vielen neuen Werken und Projekten unter seinem Namen. Also glaubte man doch, den stets neue Horizonte suchenden Meister auch im kommenden Jahrtausend bewundern zu können. Er starb aber am 16. Januar 1998 in Helsinki. Beim Begräbnis fühlte die Trauergemeinde (darunter Folkloristen aus Finnland und aus dem ihm so nahe stehenden Estland) wohl den Verlust: Einer der bekanntesten finnischen Kulturträger ist verloren.

KUUSI war in der finnischen Kulturpolitik eine Institution für sich. Ein geborener Individualist - mit tiefen Gefühlen für die lebendige Gesellschaft. Ironisch und pathetisch zugleich. Er war immer ein Kulturpessimist aber auch ein sinngebender 
Guru für Generationen von jungen Intellektuellen. Scharf in der Kritik, witzig, blitzschnell und gleichzeitig unvorhersehbar - und immer hilfsbereit. Und in solchem Masse fleißig, wie nur die alten finnischen Folkloristen es sein konnten. An einem Montag sprach er für den Feminismus in Rovaniemi, am Mittwoch argumentierte er für eine unmittelbare Folklore-Forschung in Namibien, am Donnerstag versuchte er eine finnisch-karelische Ehe zu retten, am Freitag erschienen halbbittere und eigentümliche Erinnerungen von ihm an AKS oder den Winterkrieg, über die Sitzungen an der Universität - oder über alle drei Themen, in einem Bonbonessay gepackt. Und am Dienstag? Selbstverständlich Tiistaipiiri - Dienstag-Kaffeetisch für Seminar - und Archivsmitarbeiter, Doktoranden, Gäste. Etwa 40 Jahre lang war das die wirksame Ausbildung der Folkloristen in Finnland: unvergeßlich und zugleich unnachahmbar.

Als Universitätsprofessor ,alten Stils“ beschäftigte er sich mit allen Fragen. Er selbst war Spezialist für die ostsee-finnischen epischen Gesänge und für die Kalevala. (Davon hat er auch seine eigene Version veröffentlicht!) Sein Jugendwerk eine Stilanalyse dieser Lieder (Sampo-Eepos) - ist bis heute das beste Buch über diese Dichtung. Er war Hauptredakteur des ersten Bandes der vielbändigen, großen finnischen Literaturgeschichte („Ungeschriebene Literatur") heißt sie ziemlich treffend), worin er selbst oder seine Mitarbeiter ein neues, vielseitiges, modernes und lesbares, nach Epochen und Gattungen gut proporzioniertes Bild von der finnischen Volksdichtung zu geben vermochten. Diese Ergebnisse wurden später auch mit Erfolg in einer Anthologie (The Great Bear) einem größerem Publikum auf Englisch vorgelegt. KUUSI ist Begründer der eigentlichen Poplore-Forschung in Europa. Er hat Vieles, und Tiefes über Rätsel und Witz geschrieben. Seine stilistischen, poetischen sowie metrischen Bemerkungen sind originell und werden auch heute noch nicht gebührend zitiert (und weitergeführt).

Aber sein Herzensanliegen war die Parömiologie. Seine Dissertation (Regen bei Sonnenschein) bleibt bis heute das Monument der "geographisch-historischen“ Untersuchung eines Sprichworts. Seine finnischen Proverbium Anthologien (später wurden ähnliche Anthologien auch von seinen Schülern veröffentlicht) sind nicht nur umfangreich, sondern auch voll ständig und repräsentativ. (Eine seltene Leistung!) Er hat die Fachzeitschrift Proverbium (1965-1975) ins Leben gerufen, und damit die heutige internationale Parömiologie forciert. Dort erschienen nicht nur die bahnbrechenden Aufsätze der zeitgenössischen Parömiologen, sondern auch KUUSIs eigene Forschungsideen und Reflexionen (Suum quique). Seit seinen Parömiologischen Betrachtungen (1957) fühlte KUUSI sich dazu verpflichtet, seine Ratschläge für die internationale Parömiologie immer ofenfrisch mitzuteilen. Sein Plan für einen neuen „Typenkatalog“ (Toward an International Type-System of Proverbs 1972) ist jetzt nur ein kühner Entwurf geblieben. Nach jahrzehntelanger gemeinsamer Arbeit erschien der große Index der ostseefinnischen Sprichwörter, Proverbia Septentrionalia (1985), als Krönung seiner parömiologischen Team-Arbeit. Nur die ehemaligen Mitarbeiter wissen, wieviel unveröffentlichtes Material hinter den Kulissen dieses Werkes liegt. Davon kann man nur etwas ahnen, wenn man die „M6“Fachabteilung der Bibliothek der SKS in Helsinki gründlich studiert: Die Privat- 
sammlung seiner parömiologischen Bücher. Unsere Kollegen wissen auch, wie einflußreich er z.B. bei der endlichen Veröffentlichung von Eesti vanasõnad, neben dem unermüdlichen Organisieren von kleineren, finnisch-ungarischen ParömiologieSymposien war. Um das Nachleben seines Proverbium kümmerte er sich nicht umsonst.

Seine Werke, Methode, Pläne sind auch für die Zukunft gültig. Seine Terminologie (z.B. „Parömiologie“, „Proverbium“) lebt weiter. Nur seine Persönlichkeit wird keine neuen Züge mehr zeigen. Ich vermisse ihn auch. Wir werden einander keine politischen Witze mehr erzählen, nicht mehr Dart Spielen, oder „meine“ Insel bei seinem Sommerhaus, unweit von Varkaus besuchen. 